\title{
Finitude e morte na sociedade ocidental: uma reflexão com foco nos profissionais de saúde
}

\section{Finitud y muerte en la sociedad occidental: una reflexión centrada en los profesionales de salud}

\section{Finitude and death in Western society: a reflection focusing on health professionals}

\author{
Raylane da Silva Machado ${ }^{1}$, Larissa Alves de Araújo Lima ${ }^{1}$, Grazielle Roberta Freitas da Silva ${ }^{2}$, \\ Claudete Ferreira de Souza Monteiro ${ }^{3}$, Silvana Santiago Rocha ${ }^{4}$ \\ ${ }^{1}$ Enfermeira. Mestranda em Enfermagem. Programa de Pós-Graduação em Enfermagem. \\ Universidade Federal do Piaui/UFPI. Teresina, PI, Brasil. \\ ${ }^{2}$ Enfermeira. Professora Doutora, Graduação e Pós-Graduação em Enfermagem/UFPI. Teresina (PI), Brasil. \\ Email:grazielle_roberta@yahoo.com.br \\ ${ }^{3}$ Enfermeira, Professora Doutora, Graduação e Pós-Graduação em Enfermagem/UFPI. Teresina (PI), Brasil. \\ Email: claudetefmonteiro@hotmail.com \\ ${ }^{4}$ Enfermeira, Professora Doutora, Graduação e Pós-Graduação em Enfermagem/UFPI. Teresina (PI), Brasil. \\ Email: silvanasantiago27@gmail.com
}

Cómo citar este artículo en edición digital: Da Silva Machado, R, De Araujo Lima, L.A., Freitas da Silva, G.R., De Souza Monteiro, C.F. y Rocha, S.S. (2016). Finitude e morte na sociedade ocidental: uma reflexão com foco nos profissionais de saúde. Cultura de los

Cuidados (Edición digital),20(45). Disponible en: < http://dx.doi.org/10.14198/cuid.2016.45.10.>

Correspondência: Raylane da Silva Machado. Rua Jornalista Helder Feitosa, 1131, Bloco 04, Ap 103. Bairro: Ininga. CEP: 64049-905, Teresina, PI, Brasil.

Correo electrónico: raylane.s.machado@gmail.com

Recibido: 09/012/2015; Aceptado: 12/05/2016

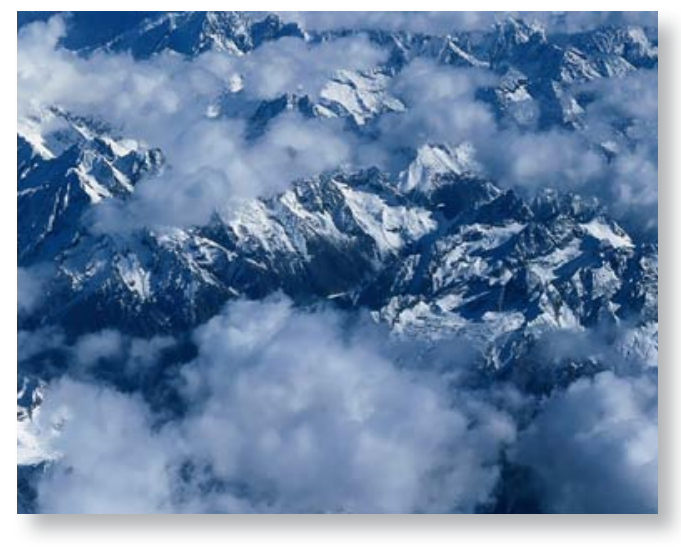

ABSTRACT

Aim: to carry out a reflection on how the vision of finitude/death in Western society influences the performance of health professionals.

Method: A reflection on death and dying is performed using the main classical authors working this issue.
Results: Death and dying are events not only biological but also of religious, social, philosophical and anthropological dimension. In Western society, there is a trend away from the idea of death, with a false belief of immortality. It is difficult to think about the issue of death and dying in their process aspects and its multiple meanings. This view implies that death is unwarranted or unexpected.

Conclusions: When we reflect directly on the practices of health professionals towards death, we understand that an opening for discussion of the topic among their peers and also is necessary to society in general. That's because these workers have turned academic training to rehabilitate and restore health with a view to prolonging life, thus envisage death as a failure, professional failure, which leads to feelings of guilt and sadness. It is important, 
therefore, that these professionals are trained scientifically and psychologically to deal with the issue.

Keywords: death, attitude to death, end of life care, health professionals, health personnel.

\section{RESUMEN}

Objetivo: hacer una reflexión sobre cómo la visión de la finitud/muerte en la sociedad occidental influye en la actuación de los profesionales de salud.

Método: Se realiza una reflexión sobre la muerte y el morir utilizando los principales autores clásicos que trabajan este tema.

Resultados: La muerte y el morir son eventos no sólo biológicos sino también de dimensión religiosa, social, filosófica y antropológica. En la sociedad occidental, hay una tendencia de alejarse a la idea de muerte, con una falsa creencia de la inmortalidad. Hay dificultad en pensar el tema de la muerte y el morir en sus aspectos de proceso y con sus múltiples significados. Este punto de vista implica en una visión de muerte injustificada o inesperada.

Conclusiones: Cuando reflexionamos directamente sobre las prácticas de los profesionales de la salud hacia la muerte, entendemos que es necesaria una abertura para la discusión del tema entre sus pares y también con la sociedad en general. Eso es debido a que estos trabajadores tienen una formación académica con foco en rehabilitar y restaurar la salud con el fin de prolongar la vida, por lo tanto vislumbran la muerte como un fracaso profesional, lo que conduce a sentimientos de culpa y tristeza. Es importante, por tanto, que estos profesionales sean capacitados científicamente y psicológicamente para hacer frente a la cuestión.

Palabras- clave: muerte, actitud frente a la muerte, cuidados fin de vida, profesional de salud, personal de salud.

\section{RESUMO}

Objetivo: realizar uma reflexão sobre como a visão de finitude/ morte na sociedade ocidental influencia na atuação dos profissionais de saúde.

Método: Foi realizada uma reflexão sobre a morte e o morrer utilizando os principais autores clássicos que trabalham essa temática.

Resultados: A morte e o morrer são eventos não apenas biológicos, mas também de dimensão religiosa, social, filosófica e antropológica. Na sociedade ocidental, há uma tendência de afastamento da ideia da morte, com uma falsa crença de imortalidade. Há dificuldade em pensar a questão da morte e do morrer em seus aspectos de processo e em suas múltiplas significações. Essa visão implica que a morte é injustificada ou inesperada.

Conclusões: Quando refletimos diretamente sobre as práticas dos profissionais de saúde perante a morte, entendemos que se faz necessária uma abertura para discussão do tema entre seus pares e também com a sociedade em geral. Isso porque esses trabalhadores possuem formação acadêmica voltada para reabilitar e restaurar a saúde com vistas ao prolongamento da vida, dessa maneira vislumbram a morte como um insucesso, fracasso profissional, que leva a sentimentos de culpa e tristeza. É relevante, portanto, que estes profissionais sejam capacitados cientifica e psicologicamente para lidar com a temática.

Palavras-chave: morte, atitude frente à morte, cuidados fim de vida, professionais de saúde, pessoal da saúde.

\section{CONSIDERAÇÕES INICIAIS}

A morte e o morrer são eventos não apenas biológicos, mas também de dimensão religiosa, social, filosófica e antropológica. O homem, 
como único animal dotado de consciência, sofre sua morte antecipadamente e, dessa maneira, o significado da morte e os mistérios que a envolvem são preocupações centrais em todas as culturas desde os tempos mais remotos.

Nessa perspectiva os profissionais da saúde merecem destaque, visto que, a presença da morte em seu cotidiano é uma constante. Eles reagem perante a ela de formas diferentes de acordo com a formação acadêmica que tiveram para lidar com o tema e com o tempo e cuidados que dispensavam a seu paciente.

Um pressuposto teórico fundamental desse artigo é que o homem é um ser de simbolismos, logo, atribui significados a situações, a objetos e também a pessoas que o rodeiam, e estes significados estão intrinsecamente relacionados com cultura em que está inserido. A morte é uma dessas situações cujas ideias, hipóteses e argumentos têm ampla relação com as características de cada cultura e período histórico (Negrini, 2014).

Dentre as referências utilizadas para construção desta reflexão citamos os principais autores clássicos que trabalharam a temática da morte e do morrer e suas obras: Sobre a morte e o morrer (Elisabeth Kübler-Ross), Sobre a História da Morte no Ocidente desde a Idade Média (Philippe Ariès) e A solidão dos moribundos seguido de Envelhecer e morrer (Norbert Elias).

Os sentimentos negativos expressos pelos homens em relação à morte podem ser aumentados ou minimizados pelo sistema cultural em que se insere. A "luta" contra a doença e a descrição comum da morte como ter "perdido a batalha" refletem uma noção moderna da morte. As sociedades contemporâneas têm cada vez mais dificuldades em pensar a questão da morte e do morrer em seus aspectos de processo e em suas múltiplas significações. Essa visão implica que a morte é injustificada ou inesperada, sendo concebida pelos profissionais de saúde como uma falha dos esforços em manter a vida (Gellie et al., 2015; Negrini, 2014).

Logo, há várias formas dos indivíduos lidarem com a ideia da finitude da vida: pode-se evitar a ideia da morte através da mitologização do final da vida, do encobrimento da ideia indesejada, pela crença na própria imortalidade ou encará-la como um fato da existência e ajustar a vida diante dessa realidade (Elias, 2001). As visões de morte com sentido de naturalidade se associam positivamente com atitude religiosa, e a morte vista como fracasso apresenta relação inversa (Diniz \& Aquino, 2009). Pessoas com crenças religiosas elevadas tendem a ter um maior grau de aceitação de morte e sentido de vida (Cicirelli, 2011).

$\mathrm{Na}$ sociedade ocidental, há uma tendência de afastamento da ideia da morte, com uma falsa crença de imortalidade. Por meio de avanços dos conhecimentos e tecnologias médicas na prevenção e do tratamento das doenças, houve um aumento considerável na expectativa de vida da população. As pessoas sobrevivem até uma idade avançada e geralmente se encaminham para morrer no hospital, em vez de em casa como ocorria no passado, o que torna mais comum aos profissionais lidarem com estas situações (Gellie et al., 2015). Considera-se também, que há um grau de antecipação e de autocontrole, o qual torna a vida previsível e cômoda. Diversamente de momentos históricos anteriores, quando a morte era acompanhada como um acontecimento corriqueiro e familiar, hoje ela é ocultada, mantida por trás dos bastidores da vida social. Os sentimentos e sua expressão se transformaram, e a morte passou a ser vista com distanciamento, quase sempre sendo negada (Elias, 2001; Gellie et al., 2015; Kovács, 2014). 
Assim, vivemos em uma sociedade que impugna a morte, além de, em sua maioria, apresentar uma visão negativa em relação a este tema. Entretanto, os profissionais de saúde a vivenciam cotidianamente. Dessa forma, este trabalho tem por objetivo realizar uma reflexão sobre como a visão de finitude na sociedade ocidental influencia na atuação dos profissionais de saúde.

\section{A construção social da morte}

Os rituais de morte ocorrem desde o princípio da humanidade, trazendo um pensamento sobre a vida após a morte, sobre a religiosidade e sobre a possibilidade de superar a morte. Indubitavelmente, estas diferentes expressões mostram a tentativa de minimizar uma separação abrupta, facilitando, assim, a superação do luto e, aproximando, o homem da morte, diminuindo o terror que esta causa.

Cada época tem parâmetros do que é a boa morte. Na Idade Média, os grandes valores eram o planejamento do morrer, com a proximidade da família, compartilhando testamentos, promovendo a continuidade dos desejos e a distribuição dos bens. Havia um envolvimento de uns na morte dos outros, pois muitas vezes o que reconfortava os moribundos era a presença de outras pessoas ao seu redor. Sem dúvida, a expressão em torno da morte era mais clara e frequente, o que não demonstra de modo algum o bom passado nem o mau presente (Elias, 2001; Kovács, 2014). A transição do local de morte, de casa para o hospital, ocorreu porque as pessoas começaram a sentir que este era o local onde mais recursos humanos e tecnológicos estavam disponíveis, para evitar que a morte ocorresse. Motivado também por um sentimento de maior segurança, pois a ideia de serem acompanhadas num hospital se relaciona com o não sofrimento nos momentos finais de vida. Com o tempo, verificou-se que a morte, em meados do século XX, transferiu-se definitivamente para os hospitais (Àries, 1989; Ferreira \& Wanderley, 2014).

São raros os familiares que mantém a tradição de levar a qualquer custo o doente para casa, para que morra em paz e com os seus; a morte no hospital é mais conveniente. A morte deixa de ser um problema familiar, afetivo e de solidariedade, para passar a ser um problema técnico (Àries, 1989). No processo civilizador, os moribundos e a morte são resolutamente banidos para os bastidores da vida social e cercados por sentimentos relativamente intensos de constrangimento e tabus verbais relativamente rígidos (Elias, 2001). No século XXI ressurge com intensidade, em virtude do prolongamento e isolamento a que são submetidos muitos pacientes, o desejo por uma morte em ambiente familiar, rápida e sem sofrimento. Ocorre uma busca pela morte com dignidade, ou seja, morrer com afirmação de valores e crenças essenciais na vida da pessoa (Kovács, 2014).

Entretanto, o que se observa é que ocorre uma medicalização da morte, evitando que ela ocorra de forma pacífica e por causas naturais, como muitos desejam. Isso ocorre devido a uma fragmentação do cuidado associado a uma complexidade crescente de processos médicos, que podem resultar em desejos dos pacientes perdidos ou negligenciados, como no caso de uma não ressuscitação (Gellie et al., 2015). Dessa maneira, faz-se necessário trabalhar junto aos profissionais de saúde conhecimentos, habilidades e atitudes com vistas ao desenvolvimento de uma competência profissional, como também do cuidado humanizado, para assim garantir o acompanhamento do paciente a uma morte digna. 


\section{Os profissionais de saúde frente à morte}

Os hospitais ao assumirem progressivamente a imagem de um local adequado para uma melhor morte, fez com que esta se tornasse mais remota e oculta do olhar de todos que não exercem funções profissionais no ambiente hospitalar. Assim a necessidade de lidar com a morte é uma faceta fulcral quando se trabalha com saúde (Ferreira \& Wanderley, 2014).

Ao longo de toda a sua formação, o discente da área de saúde é preparado acadêmica e profissionalmente para salvar pacientes, para lhes retirar a dor, o sofrimento e a doença, evitando a morte a todo custo. Quando confrontados com situações em que os seus esforços profissionais não conseguem conduzir o paciente a nenhum dos cenários idealizados, esse profissional vai sentir-se pouco capaz e desiludido.

Para além do contato com a morte antecipada, a morte efetiva de pacientes com os quais os profissionais tinham relações mais próximas, a morte de pacientes que não se conseguiu "curar" apesar de todos os esforços realizados, a morte de pacientes jovens ou as mortes ocorridas com menos dignidade do que se desejava, podem gerar níveis elevados de angústia. Se a morte é vista como um fracasso ou indignidade, o profissional se vê perdendo batalhas e derrotado (Kovács, 2014).

Todos esses fatores contribuem para que o trabalhar em contexto hospitalar e lidar com a morte sejam condições suficientemente capazes de produzir sofrimento, ou então, distanciamento dos profissionais em relação àqueles que são cuidados. Por isso, é necessário despertar o olhar para os sentimentos e sensações que lidar com o morrer causa nesses indivíduos.

Um dos problemas da sociedade ocidental atual é a incapacidade de dar aos moribundos a ajuda e afeição que eles tanto necessitam no fim de suas vidas, isso porque ver a morte do outro é lembrar a sua finitude e a de seus entes queridos. Desse modo, "o problema social da morte é especialmente difícil de resolver porque os vivos não conseguem identificar-se com os moribundos" (Elias, 2001, p.9). Assim, um dos elementos mais presentes que causam consequências para a sociedade é a questão do medo. Medo da própria morte, da morte do outro, de como vai morrer, enfim. Tendo em vista esse sentimento, é relevante entender como os profissionais da saúde reagem frente à morte de seus pacientes e o impacto provocado. Alguns profissionais demonstram atitude de negação em relação à morte, outros buscam naturalizá-la e a cada vivência, fortificar-se. Morrer tem sua dualidade para os profissionais, por um lado é gerador de tristeza, impotência, medo, dor e insucesso e por outro de alívio e libertação tanto para a família quanto para o paciente (Alves et al., 2012; Mota et al., 2011; Oliveira et al., 2013).

Em uma revisão de literatura voltada para identificar as atitudes perante a morte em profissionais de enfermagem, constatou-se que o assunto "morte e morrer" está sendo negligenciado nas instituições de formação e isso repercute na prática profissional, visto que devido a falta de preparo, afloram dificuldades e sofrimentos vivenciados por profissionais e acadêmicos. A pouca atenção conferida à temática repercute sobre a conduta adotada frente ao paciente que, por vezes, se torna fria, distante, impessoal e tecnicista. A exposição contínua e constante ao estresse gerado pelo contato cotidiano com a morte e o morrer dos pacientes, sem que haja dispositivos protetores institucionalizados para seu alívio e elaboração, pode afetar a saúde mental dos profissionais (Santos \& Hormanez, 2013). 
Mota et al., (2011) afirma que os profissionais de enfermagem, por exemplo, não se sentem a vontade em preparar o corpo do paciente e recebem este procedimento como uma forma de punição por não terem conseguido evitar a morte. Isto é um fator preocupante para o desenvolvimento de doenças, como a síndrome de Burnout, causada pelo estresse, ou mesmo depressão nos profissionais que precisam lidar diariamente com essas situações e não sabem como a enfrentá-las da melhor maneira possível.

Dessa forma, percebe-se que os profissionais da saúde também se envolvem com os pacientes e comumente sofrem ao vivenciar ou mesmo perspectivar a morte de quem cuidam. Evidencia-se assim, a necessidade de capacitação para os profissionais quanto à tanatologia, formação de grupos que favoreçam a troca de experiências, reflexões e discussões entre os profissionais como um elemento de suporte e fortalecedor ao trabalhador que vivencia essas situações diariamente. Essa formação deverá prepará-los para promoverem uma morte digna e humanizada de todos os que vivenciarem o processo de morrer sob seus cuidados.

A morte humanizada foi abordada inicialmente pela sueca Elisabeth Kübler-Ross, que realizou pesquisas com pessoas em momentos finais de vida e seus familiares, estudando todo o processo de morrer e da morte. A autora também descreve sua experiência como psiquiatra no acompanhamento de pacientes gravemente enfermos e apresenta os cinco estágios do luto (negação, raiva, barganha, depressão e aceitação).

A externalização dos sentimentos em relação à morte pelos indivíduos e a compreensão desses afetos pelos que o acompanham são fundamentais para a sua aceitação. Essa compreensão significa evitar frases do tipo "não fi- que triste", entendendo esta tristeza vinculada ao processo de perda de tudo, de todos e da própria vida pelo qual está passando o paciente. Apesar do processo de terminalidade, a autora ressalta que persiste em todos os estágios a esperança. E é justamente essa esperança que dá a sensação de que tudo deve ter um sentido e os fazem suportar. Isso não significa que os profissionais devam mentir. Deve-se apenas fazer sua a esperança do paciente (Kübler-Ross, 2008).

É importante e necessário, também, que o paciente possa manter sua autonomia, podendo inclusive rejeitar tratamentos; continuar exercendo suas maiores habilidades, mesmo com ajuda de outras pessoas; e também continuar a satisfazer seus desejos; e ter direito a conduzir sua própria morte (Gellie et al., 2015; Kübler-Ross, 2008; Kovács, 2014). O entendimento desses fatores configura-se como um passo fundamental para o desenvolvimento profissional e um adequado lidar com o processo de morte e morrer.

Atualmente, a formação para cuidados paliativos vêm justamente para preencher esta lacuna existente entre a morte vista apenas como o fracasso do tratamento e a morte observada sob a perspectiva de dar uma assistência humanizada e de qualidade. Dessa forma, há uma harmonização entre a competência técnica da medicina (com a cura) e a cultura do respeito à autonomia do paciente no que se refere às suas decisões de sua saúde e de sua vida.

\section{CONSIDERAÇÕES FINAIS}

Historicamente, as maneiras de lidar com terminalidade tem se modificado o que levou, ao longo da evolução social da humanidade, a um progressivo distanciamento de tudo que se relacionasse com a temática da morte. 
A forma de reagir à situação de finitude depende da cultura, das crenças e da formação das pessoas para isso. Quando refletimos diretamente sobre as práticas dos profissionais de saúde perante a morte, entendemos que se faz necessária uma abertura para discussão do tema entre seus pares e também com a sociedade em geral. Isso porque esses trabalhadores possuem formação acadêmica voltada para reabilitar e restaurar a saúde com vistas ao prolongamento da vida, dessa maneira vislumbram a morte como um insucesso, fracasso profissional, que leva a sentimentos de culpa e tristeza.

É relevante, portanto, que estes profissionais sejam capacitados cientifica e psicologicamente para lidar com o morrer de seus pacientes. Destaca-se, para este fim, o desenvolvimento de grupos com os profissionais da saúde para discussão deste tema com o objetivo da troca de experiências e vivências que permitam um melhor enfrentamento da morte dentro do ambiente hospitalar.

\section{REFERÊNCIAS}

- Alves, M.V.M.F.F., Scudeler, D.N., Luppi, C.H.B., Nitsche, M.J.T. y Toso, L.A.R. (2012). Morte e morrer em unidade de terapia intensiva pediátrica: percepção dos profissionais de saúde. Cogitare Enfermagem, 17(3), 5438. Recuperado de: http://ojs.c3sl.ufpr.br/ojs/index. php/ cogitare/article/view/29296

- Ariés, P. (1989). Sobre a História da Morte no Ocidente desde a Idade Média. Lisboa: Teorema.

- Cicirelli, V.G. (2011). Religious and nonreligious spirituality in relation to Death acceptance or rejection. Death Studies, 35(2), 124-146. Recuperado de: http:// www.ncbi.nlm.nih.gov/pubmed/24501832

- Diniz, A.C. y Aquino, T.A.A. (2009). A relação da religiosidade com as visões de morte. Religare, 6(2), 101-113. Recuperado de: http://periodicos.ufpb.br/ojs/ index.php/religare/ article/view/8238

- Elias, N. (2001). A Solidão dos moribundos seguido de envelhecer e morrer. Rio de Janeiro: Jorge Zahar Editor.

- Ferreira, A.M.Y. y Wanderley, K. S. (2014). About death and dying: a space for observation. Journal Kairós Gerontologia, 17(Special Issue 17), 169-180.
- Gellie, A., Mills, A., Levinson, M., Stephenson, G. y Flynn, E. (2015). Death: a foe to be conquered? Questioning the paradigm. Age and Ageing, 44(1), 7-10.

- Kovács, M.J. (2014). A caminho da morte com dignidade no século XXI. Revista Bioética, 22(1), 94-104. Recuperado de: http://revistabioetica.cfm.org.br/index. $\mathrm{php} /$ revistabioetica /article/view/886

- Kübler-Ross, E. (2008). Sobre a morte e o morrer: o que os doentes terminais têm para ensinar a médicos, enfermeiras, religiosos e aos seus próprios parentes. São Paulo: WMF Martins Fontes.

- Mota, M.S., Gomes, G.C., Coelho, M.F., Lunardi Filho, W.D. y Sousa, L.D. (2011). Reações e sentimentos de profissionais da enfermagem frente à morte dos pacientes sob seus cuidados. Revista Gaúcha de Enfermagem, 32(1), 120-35.

- Negrini, M. (2014). A significação da morte: um olhar sobre a finitude humana. Sociais e Humanas, 27(1), 2936.

- Oliveira, P.P., Amaral, J.G., Viegas, S.M.F. y Rodrigues, A.B. (2013). Percepção dos profissionais que atuam numa instituição de longa permanência para idosos sobre a morte e o morrer. Ciência \& Saúde Coletiva, 18(9), 26352644.

- Santos, M.A. y Hormanez, M. (2013). Atitude frente à morte em profissionais e estudantes de enfermagem: revisão da produção científica da última década. Ciência \& Saúde Coletiva, 18(9), 2757-2768. Recuperado de: http:// www.scielo.br/scielo.php?pid=S1413812320130009 00031\&script=sci_arttext 